\title{
Spring Meeting Symposia Summaries
}

\author{
Topics and Trends in Electronic Materials and Surface Analysis Reviewed in Seven Symposia
}

\section{Ion Beam Processes in Advanced Electronic Materials and Device Technology} (Symposium A)
Symposium Organizers: B. R. Appleton, Oak Ridge National Laboratory; F. H. Eisen, Rockwell International; T. W. Sigmon, Stanford Electronics Laboratory.

This symposium was organized to address the ion beam processing and associated annealing problems of current importance in the fabrication of state-of-the-art semiconductor devices. The conference format consisted of an opening Plenary Session which presented a broad overview, followed by eight topical sessions focusing on specific areas with in-depth technical coverage. All papers were invited or contributed oral presentations.

The opening Plenary Session on Monday morning contained four invited talks. Prof. Jim Gibbons of Stanford Electronics Laboratories presented a comprehensive review of calculated range and damage distributions using the Boltzmann transport equation approach. The results encompassed multilayer targets of general interest for semiconductor fabrication and showed that difficult phenomena such as large-angle scattering and channeling effects can be reasonably modeled and calculated. Prof. Jim Mayer from Cornell University reviewed the tremendous range of investigations possible in regrowth of implanted silicon. The review covered furnace annealing, rapid thermal annealing, and pulsed-laser annealing techniques, and the many experimental methods employed to study regrowth with these techniques at rates varying from $10^{-10}$ to $10 \mathrm{~m} / \mathrm{s}$.

The effects of implanted impurities on recrystallization were also assessed. Dr. Tom Seidel from J. C. Schumacher Co. covered the most recent results in shallow junction control using rapid thermal annealing (RTA). His review showed that shallower defect-free junctions are possible with RTA than with conventional thermal annealing techniques. He also covered effects such as enhanced diffusion of implanted B during RTA, and RTA of chemically deposited dopants. The final Plenary Session review was presented by Prof. Ben Streetman of the University of Texas, Austin. He reviewed the prospects emerging from ion implantation and annealing in III-V multilayer heterostructures. Not only has the early work in this field shown great potential resulting in the fabrication of several device structures, but it has raised many challenging research questions in understanding the device processing problems associated with ion implantation and annealing of multilayer structures. This appears to be an area of considerable challenge in the next few years for both the processing scientists and the device engineers.
The remaining program included sessions on:

- Focused Beams (chaired by Dr. R. F. Pease) in which Prof. Kenji Gamo of Osaka University reviewed recent advances in the use of focused ion beams for maskless microfabrication.

- Shallow Junctions, Channeling Tails and Amorphous Layer Regrowth (chaired by Dr. J. S. Williams) in which many of the origins and solutions to shallow junction fabrication were evaluated. - Ion Beam Mixing, Modification and Adhesion in Metal/Insulator/ Semiconductor Systems (chaired by Drs. J. Amano and B. M. Paine). The two invited talks in this session were by Dr. Gary Farlow from Oak Ridge National Laboratory who addressed the materials aspects of ion beam mixing of metal films on insulators important in electronic packaging, and Dr. T. Venkatesan from Bell Communications Research who reviewed the modification and transport mechanisms which occur in ion bombarded polymers

- High Dose Rate and High Energy Implantation Effects (chaired by T. E. Seidel). Dr. Jim Williams of the Microelectronics Technology Center in Melbourne, Australia, offered an invited overview of recent experiments on solid-phase epitaxial crystallization of silicon induced by irradiation with energetic ions. These and other high dose rate effects such as radiation-induced transport, sputtering, and beam annealing were presented in the contributed portion of the session.

- Implantation in Compound Semiconductor Materials and Devices (chaired by Dr. C. E. Evans). The invited overview by Dr. Eirug Davies covered the formidable problems associated with successful annealing of implanted III-V compounds and the promise of RTA techniques.

- Buried Insulating Layers, SOS, and SOI (chaired by Dr. D. K. Sadana). Papers in this session explored the fabrication, defect structures, and annealing behavior of buried insulating layers formed by ion implantation as well as SOS and SOI structures.

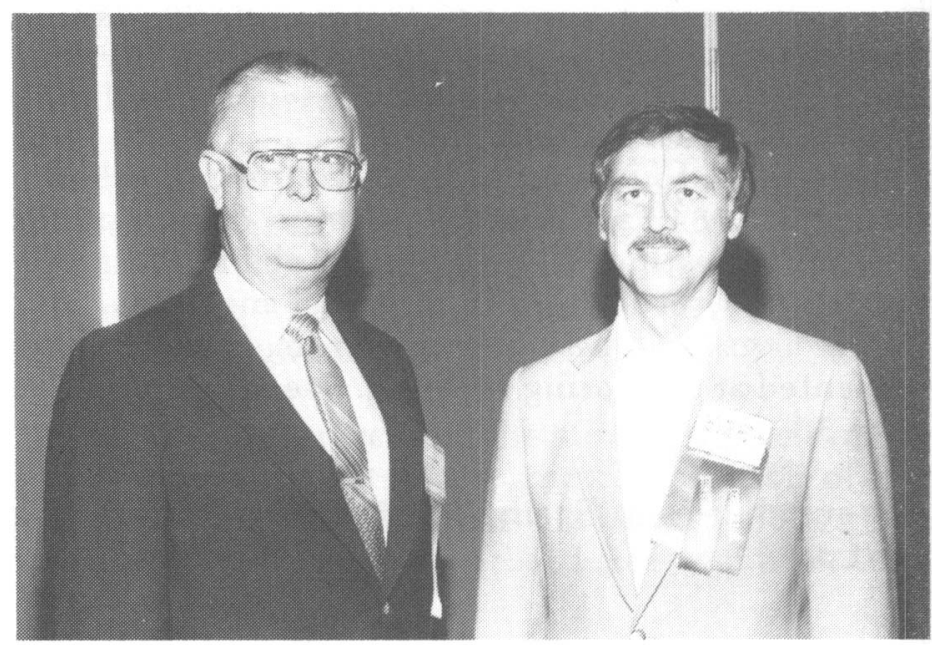

Symposium A Chairpersons (left to right) F. H. Eisen and B. R. Appleton. 
- Practical Machine and Implant Considerations (chaired by Dr. M. L. Current). Dr. Geoff Ryding of Eaton Corporation reviewed the equipment and measurement techniques utilized in present implantation applications as well as new high-current accelerators being designed for fabricating buried insulating layers.

- Transient Thermal Annealing (chaired by Prof. J. Washburn). Papers in this session presented an in-depth view of the transport, annealing, and electrical characteristics of implanted dopants as a consequence of rapid thermal annealing.

The program and participation in Symposium $\mathrm{A}$ was international, interdisciplinary, and very interactive. Approximately $37 \%$ of the papers were from institutions and laboratories outside the United States. The participation was nearly evenly divided between industrial and university participants. The discussions in the various sessions showed a directed exchange of ideas and research directions that suggested the original organizational goals of the symposium were met and that future meetings in this area should be well received.

Symposium Support: Army Research Office, Metallurgy and Materials Science Division; Division of Materials Science, Office of Basic Energy Sciences, U. S. Department of Energy; National Electrostatics Corporation; and Rockwell International.

Proceedings: Ion Beam Proctses in Advanial Electronic Materials and Devic Trihnulogy, edited by F. H. Eisen, T. W. Sigmon, and B. R. Appleton. Prices until August 1: MRS members-\$30, U.S. nonmembers-\$36, foreign nonmembers-\$42. Prices after August 1: MRS members-\$35, U.S nonmembers $-\$ 42$, foreign nonmembers $-\$ 48$.

\section{Microscopic Identification of Electronic Defects in Semiconductors}

\section{(Symposium B)}

Symposium Organizers: N. M. Johnson, Xerox Palo Alto Research Center; S. G. Bishop, Naval Research Laboratory; and G. D. Watkins, Lehigh University.

The symposium on Microscopic Identification of Electronic Defects in Semiconductors reviewed a broad range of experimental techniques for the identification of electronic defects in elemental and compound semiconductors and addressed the role of theory in electronic defect identification. Major topics of discussion included native defects in III-V semiconductors, thermal donors in silicon, transition metal impurities in semiconductors, and defects at semiconductor interfaces.

The symposium included 16 invited papers, 28 orally presented contributed papers, and 32 contributed poster papers which were presented in a very successful evening session. One of the highlights of the symposium was the opening Keynote Session in which Kim Kimerling (AT\&T Bell Laboratories), Jurgen Schneider (Fraunhofer-Institut für Angewandte Festkörperphysik), and Maurice Skolnick (Royal Signals and Radar Establishment) reviewed the effectiveness of junction spectroscopy, magnetic resonance, and various optical spectroscopies for defect identification. The unifying theme of this session, as presented by Hermann Grimmeiss (University of Lund), was the recognition of the need for the concerted application of all available experimental techniques in order to achieve a detailed understanding of defects in semiconductors. In addition, the level of specificity and detail in the information

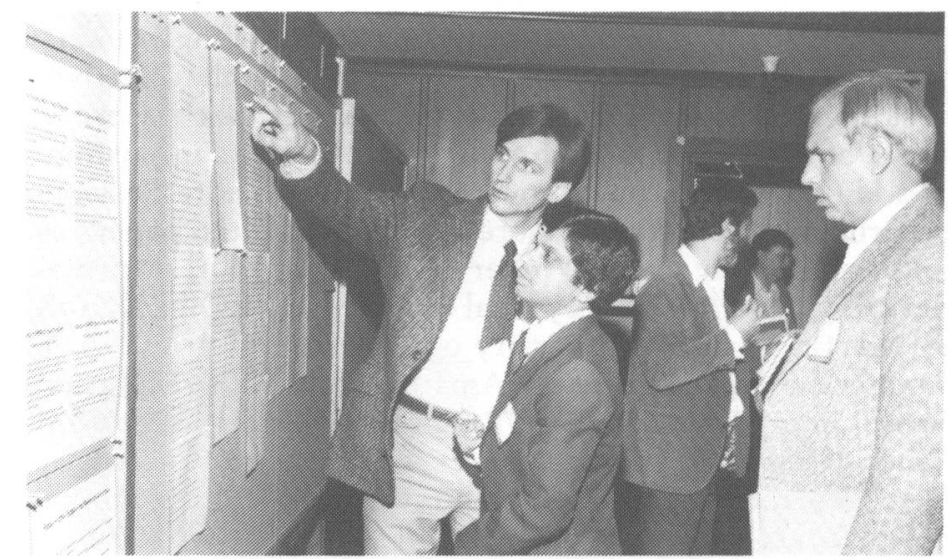

provided by various spectroscopies is being enhanced substantially by carrying out experiments in the presence of perturbations such as uniaxial stress or magnetic field.

This experimental session was complemented by an afternoon session covering the role of theory in defect identification. The successes, failures, and inherent limitations of various calculational techniques for the study of the electronic structure of defects and the thermodynamics of deep levels were discussed in invited papers by Michael Schluter (AT\&T Bell Laboratories), Jack Dow (University of Notre Dame), and Jim Van Vechten (IBM).

An entire session, including two invited papers, was devoted to EL2, the main electron trap in GaAs, and its possible relationship to the arsenic antisite defect. Harry Gatos (MIT) summarized the progress that has been made in understanding this important defect. It has been established that EL2 is a deep donor which is responsible for the semi-insulating property of undoped GaAs. Its concentration can be controlled through the melt stoichiometry, and it seems to be associated with the arsenic antisite defect. There remain some very vexing uncertainties. Is EL2 a unique defect or a "family" of defects? Is EL2 the isolated arsenic antisite and if so is the defect distorted? Is EL2 an association or complex of the arsenic antisite with other native defects or impurities?

The impression gained from the papers concerning group IV semiconductors is that progress in the theoretical and experimental elucidation of the electronic structure of complex defects in these materials (in particular, thermal donors in silicon) has been very substantial.

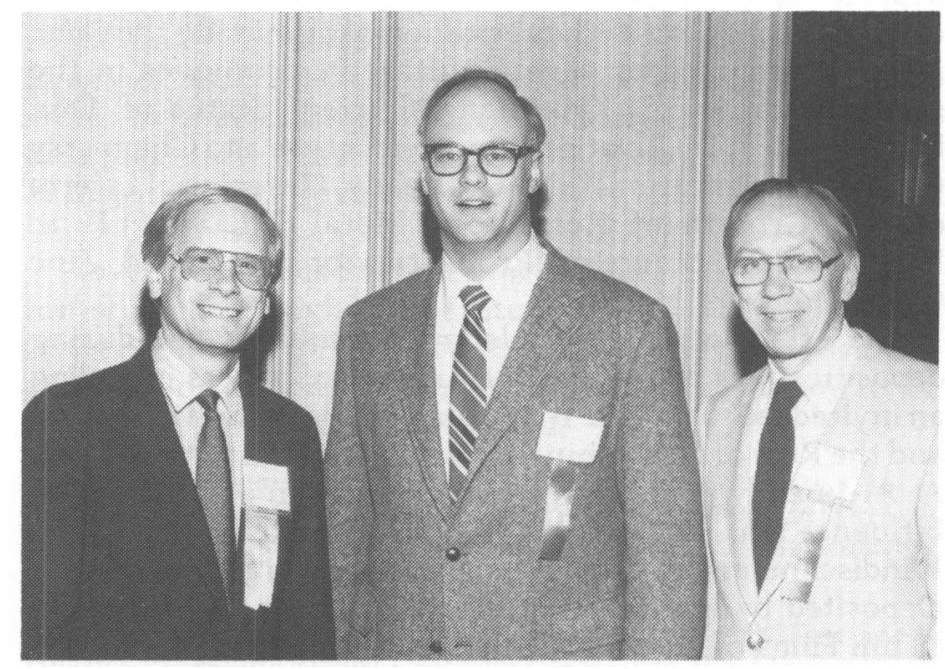

Symposium B Chairpersons (left to right) S. G. Bishop, N. M. Johnson, and G. D. Watkins. 
Participants commented on the uniformly high quality of the invited presentations and, particularly, on the effectiveness of scheduling informative reviews of such a broad range of experimental tech niques in the same symposium. In addition to the topics covered in the Keynote Session, experimental techniques were treated in invited papers as follows: EPR by Eiche Weber (University of CaliforniaBerkeley), EPR/ODMR by Neal Wilsey (NRL), ODENDOR by Martin Spaeth (University of Paderborn) and C. A. J. Ammerlaan (University of Amsterdam), high-resolution photoluminescence by Don Reynolds (AFWAL) and Rolf Sauer (University of Stuttgart), electron microscopy by Pierre Petroff (AT\&T Bell Laboratories), local vibrational mode spectroscopy by Ron Newman (University of Reading), and characterization of high-purity semiconductors by Gene Haller (University of CaliforniaBerkeley).

Symposium Support:Army Research Office, Electronics Division, Office of Naval Research, Air Force Office of Scientific Research, Xerox Corporation.

Proceedings: Microscopic Identification of Electronic Defects in Semiconductors, edited by N. M. Johnson, S. G. Bishop, and G. D. Watkins. Prices until August 1: MRS members-\$36, U.S. nonmembers-\$43, foreign nonmembers $-\$ 50$. Prices after August 1: MRS members-\$41, U.S nonmembers $-\$ 50$, foreign nonmembers $-\$ 57$.

\section{Thin Films: The Relationship of Structure to Properties (Symposium C)}

Symposium Organizers: C. R. Aita, University of WisconsinMilwaukee; and K. S. SreeHarsha, San Jose State University.

Thirty-seven papers distributed over six sessions were presented in Symposium C, Thin Films: The Relationship of Structure to Properties. Emphasis was placed on the effect of atomic order, or lack thereof, on derived properties such as electrical, optical, and adhesion behavior.

A wide variety of materials was discussed including metal, alloy, and layered films, modern ceramic materials, ordered and amorphous semiconductors, and silicides and related compounds. Papers based on film growth by thermal and electron beam, evaporation, reactive sputtering, ion beam sputtering, molecular beam epitaxy, chemical vapor deposition, and electrodeposition were presented. Several invited papers dealt with fabrication of nominally the same material prepared by several different techniques in the same laboratory (E. Krikorian, "Current Status of Thin Film $\mathrm{Hg}_{1-\mathrm{x}} \mathrm{Cd}_{\mathrm{x}} \mathrm{Te}$ : Relationship of Structure and Chemistry to Device Applications"; M. G. Lagally, "Interfacial Effects on the Growth of Refractory Metal Silicides"; F. S. Hickernell, "Structural Properties of Sputtered Zinc Oxide.")

The effect of ion and electron bombardment during deposition was addressed in a number of papers including an invited talk by J. E. E. Baglin on "Ion Beam Enhancement and the Role of Contaminants" and contributed talks by G. A. Al-Jumaily et al., "Ion Beam Deposition of Thin Films: Influence on Surface and Volume Microstructure"; $H$. Windischmann et al., "Crystallization of a-Si and a-Ge Deposited by Ion Beam Sputtering"; D. R. Kerwin et al., "Thin Films of Diamond-Like Carbon"; and D. K. Sood et al., "Modication of Thin Films and Interface Properties under Irradiation."

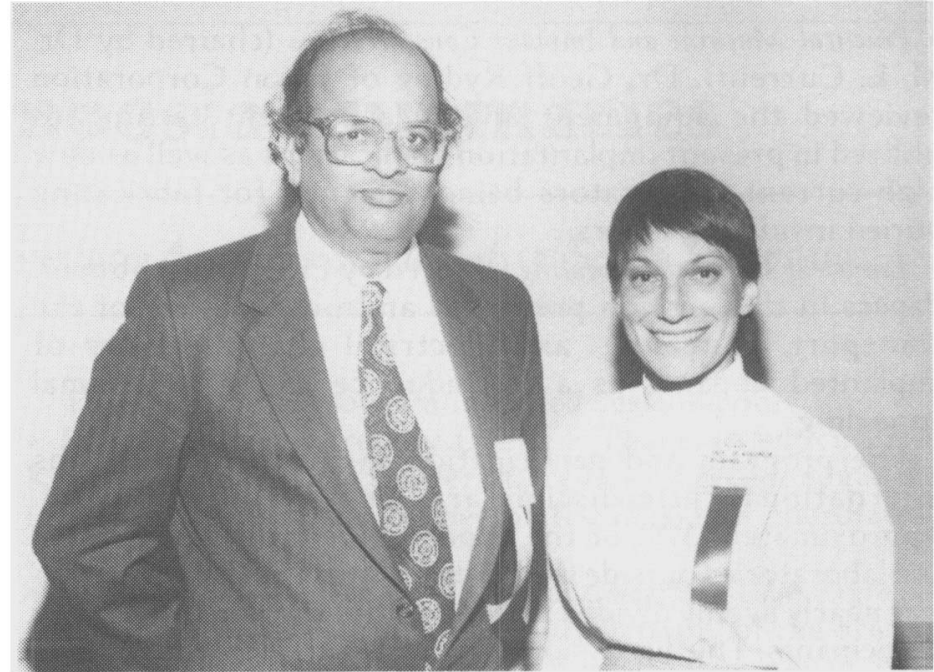

Symposium C Chairpersons (left to right) K. S. SreeHarsha and C. R. Aita.

Four invited speakers dealt with different aspects of semiconductor chemistry and structure: T. L. Barr et al., "ESCA Studies of the Valence Band and Loss Spectra of Semiconductor Films: Ionicity and Chemical Bond ing"; P. H. Holloway, "Chemical Composition and Electrical Behavior of Schottky Contacts to GaAs"; J. Merz, "The Visible and Invisible of Compound Semiconductors: Defects and Other Effects"; and J. C. Phillips, "Microstructure and Doping of Amorphous Silicon." Two invited speakers dealt with the application of thermodynamics to thin film systems: D. Gupta, "Special Aspects of Diffusion in Polycrystalline and Amorphous Metallic Films at Low Temperature"; and R. Beyers, "Thermodynamic Considerations in Thin-Film Metallizations."

Two out of the five Graduate Student Awards presented at the 1985 MRS Spring Meeting were received by participants of Symposium C: E. D. Marshall for his contribution to "Metal-Germanium Contacts and Germinide Formation" and C. J. G. Kubiak for her contribution to "Optical Behavior of Sputter Deposited Aluminum Nitride: Relationship to Film Chemistry."

Symposium Support: Data General and Gould AMI Semiconductors.

Proceedings: Thin Films: The Relationship of Structure to Properties,

edited by C. R. Aita, and K. S. SreeHarsha. Prices until August 1: MRS members $-\$ 25$, U.S. nonmembers $-\$ 30$, foreign nonmembers $-\$ 35$. Prices after August 1: MRS members $-\$ 30$, U.S. nonmembers $-\$ 35$, foreign nonmembers $-\$ 42$.

\section{Mass Memory Technologies (Symposium D)}

Symposium Organizers: M. A. Bosch, Balzers; I. M. Croll, IBM; D. H. Davies, $3 M$; R. D. Hilde, $3 M$ : and A. Homola, IBM.

The symposium on Mass Memory Technologies consisted of 38 papers spanning two basic topics-optical data and magnetic recording. The following summarizes the highlights of the optical data section. Emphasis of the industry is pointed at environmental stability, magneto-optic and phase change eraseable materials and understanding of this mechanism of failure.

The paper "Thermal Stability and the Role of Oxygen in Magneto-optic Films" by T. Anthony, S. Naberhuis, J. Brug, and H. Birecki of Hewlett-Packard, presented media structure and materials and proposed mechanism for 


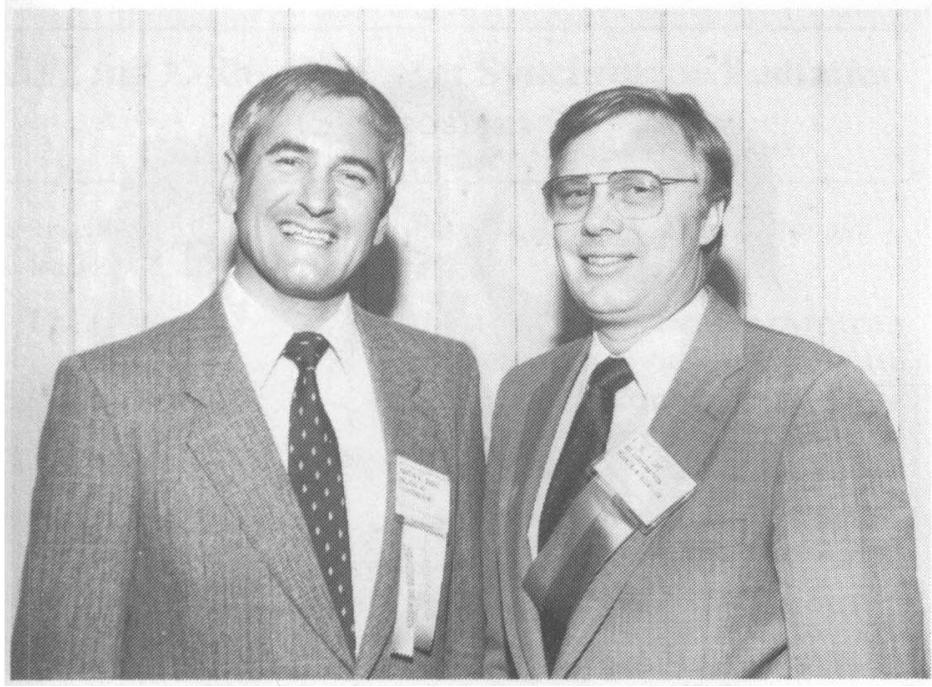

Symposium D Chairpersons (left to right) M. A. Bosch and R. D. Hilde.

degradation of properties. They offered experimental results to support the theory. "Laser Recording in Tellurium Suboxide Thin Films," by Y. S. Tyan, D. R. Preuss, and F. Vazan of Eastman Kodak, discussed materials and media structure and proposed a new theory on writing mechanism. The authors showed micrographs and diffraction patterns to support their theory. G. Alphonse of RCA Laboratories discussed "Thermal Considerations for the Design of Multilayer Optical Disks." He presented a mathematical model for deriving write power needed for different material stacks and showed calculated values of write power for four specific materials systems. This type of theoretical work opens many new and interesting doors for research.

"Phase Transformation Kinetics of Tellurium and Tellurium Alloys," by K. A. Rubin, R. Barton, D. Rugar, M. Chen, V. Jipson, and T. Dewey of IBM, discussed media structure and materials and showed interesting experimental results in phase transformation kinetics diagrams (PTK).

Symposium Support: 3M, IBM, Symard.

\section{Applied Materials Characterization} (Symposium E)

Symposium Organizers: W. Katz, General Electric Company; and P. Williams, Arizona State University.

Forty-eight papers were presented in the three-day symposium on Applied Materials Characterization, dealing both with the development of advanced characterization techniques and application of characterization technology to advanced materials. Increasingly, materials characterization must deal with questions at the atomic level, and in many areas the thrust is to shrink the area from which information is obtained to the atomic limits. In addition to describing his elegant technique for deriving surface microstructural information from low-energy electron diffraction (LEED) data, Max Lagally (University of Wisconsin) also showed that significantly more information is obtained by shrinking the dimensions of the LEED probe. John Spence (Arizona State University) discussed his new technique for atom location by chan-

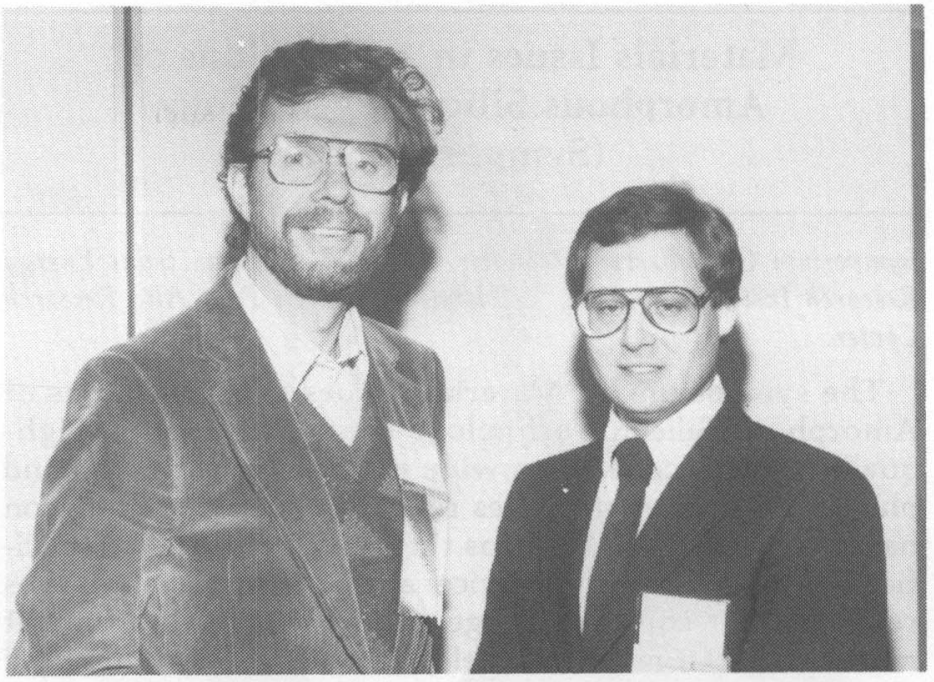

Symposium E Chairpersons (left to right) P. Williams and W. Katz.

nelling-enhanced radiation (ALCHEMI) which allows lat tice locations to be determined in the small sample volumes probed in the electron microscope.

Characterization with sub-nanometer resolution in the electron microscope was discussed by M. Isaacson (Cornell University). Walter Gibson (SUNY-Albany) discussed $x$ ray standing-wave interference spectroscopy (XSWIS), which is almost the only technique now capable of probing structure at the solid-liquid interface with atomic resolution. The ultimate, of course, is atomic resolution microscopy of single atoms, and the use of field ion microscopy to study the diffusion and interaction of silicon-metal clusters on tungsten was described by J. D. Wrigley (University of Illinois).

Particularly in semiconductor devices, the capability for three-dimensional characterization with resolution on the scale of the device (sub-micron laterally, nanometers in depth) is desirable. A microbeam Rutherford backscattering facility has been developed at the University of Melbourne, and its impressive capabilities were described by J. S. Williams.

Another frontier area is in the characterization of trace impurities. Here secondary ion mass spectrometry, as reviewed by $C$. W. Magee (RCA), is gaining increasingly broad applicability, while newer techniques such as the laser microprobe are finding an important niche for surface contamination studies in particular (C.W. Hitzman, Charles Evans \& Associates). Laser photoionization of sputtered atoms is a promising new trace analysis technique; approaches using resonant and non-resonant multiphoton absorption were reviewed by $\mathrm{N}$. Winograd (Pennsylvania State University) and C. H. Becker (SRI).

Novel techniques discussed included Raman spectroscopy for studies of high-temperature phase transitions, and conversion-electron Mössbauer spectroscopy and positronannihilation studies, both of which were shown to be promising surface analytical tools.

Symposium Support: A. G. Associates, Cameca Instruments, Charles Evans \& Assoeiates, General Ionex, JEOL, Perkin Elmer-Physical Electronic Division, Philips, Surface Science Instruments, V. G. Instruments, Instruments, S.A., Leybold-Heraeus, Inc.

Proceedings: Applied Materials Characterization, edited by W. Katz and P Williams. Prices until August 1: MRS members-\$36, U.S. nonmembers$\$ 43$, foreign non members - $\$ 50$. Prices after August 1: MRS members$\$ 41$, U.S. nonmembers $-\$ 50$, foreign nonmembers $-\$ 57$. 


\section{Materials Issues in Applications of Amorphous Silicon Technology (Symposium F)}

Symposium Organizers: D. Adler, MIT; A. Madan, Solar Energy Research Institute; and M. J. Thompson, Xerox Palo Alto Research Center.

The symposium on Materials Issues in Applications of Amorphous Silicon Technology contained over 60 highquality papers covering a wide range of applications and physics and materials issues related to amorphous silicon based technologies. This was the first conference to specifically concentrate on device and the materials issues related to the complete range of applications of a-Si:H. It marks a milestone in this field, and its success illustrated the maturity of this technology. Throughout the three days, the sessions were well attended by an international audience of 150-200 which generated some lively discussions.

Excellent reviews were given of recent developments in amorphous silicon solar cell technology. The methods to improve cell efficiency emphasizing amorphous silicon alloys stacked and triple solar cell structures were described as well as mass production processes employing laser scribing for microfabrication. It was pointed out that many materials issues are involved in this technology in addition to improvement in the a-Si:H and its alloys. Purity of the starting gas can play a role in cell stability. The properties of the substrate and the texture of the $\mathrm{TO}$ as well as the encapsulant all can affect performance of the final power module product. High-performance solar cells have been produced of efficiency $11 \%$ which incorporate a photo CVD p layer.

A new theory was advanced for the effect of deposition sequence on $\mathrm{p}-\mathrm{i}-\mathrm{n}$ cell performance. Solar cells produced from higher order silanes were described, and an excellent review of light-induced metastable defects was given. The influence of impurities, band bending, doping, compensation, and mechanical stress were described in detail, and suggestions for enhancing device stability were made. Another presentation reported a method to improve stability by graded boron doping of the i layer, and capacitance studies of light-induced effects addressed the issues of whether the dangling bonds were the main influence on stability. The status of multilayer superlattice structures was reviewed, in addition to an update on the recent results on persistent photoconductivity in these structures.

Seven papers discussed TFTs and devices for addressing liquid crystal displays. The present status was reviewed in which the similarity between TFT data from different laboratories was emphasized. There appears to be no major lifetime issues and the remaining goals appear to be directed towards improving yield and making larger displays. Some novel sandwich TFT structures were described which had high current capability but some capacitance and/or technology issues remain to be resolved.

Comprehensive reviews of photoreceptor, vidicon, and image sensor technology were given, including discussion of issues of enhancement of photoresponse in the photoreceptor by using $\mathrm{SiGeFH}$, the influence of the blocking layer contact on photoreceptor performance, and a microwave high-rate deposition system. a-Si:H linear image

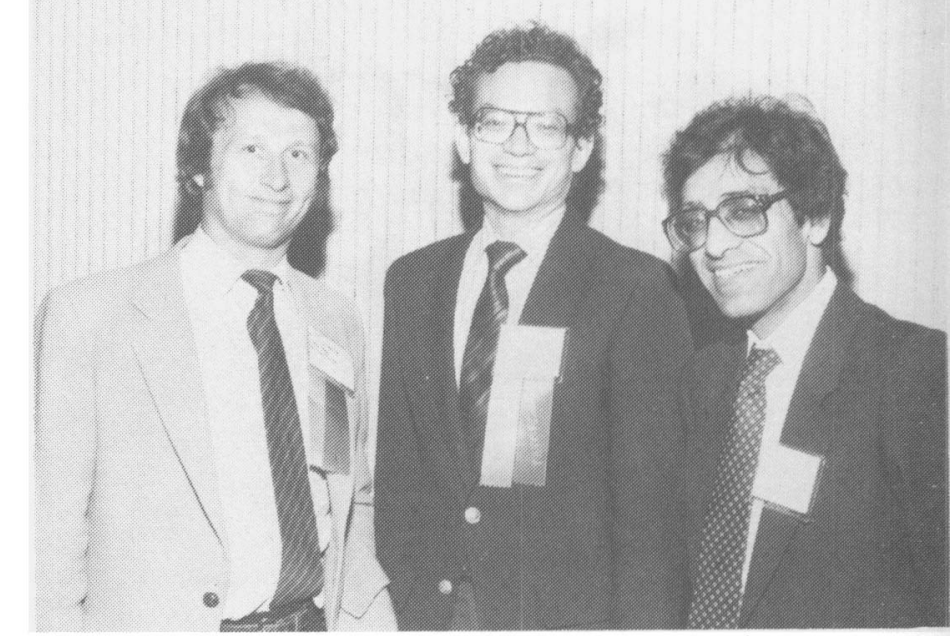

Symposium F Chairpersons (left to right) M. J. Thompson, D. Adler, and A. Madan.

sensor rays (A4 \& B4 width) of resolution 200 spi are now in mass production for document reader and telecopy applications. A range of papers reported on silicon devices such as Schottky barriers, switching devices, polysilicon TFTs, and a-Si:H as emitters in bipolar transistors.

Thirteen papers spanned topics in alloys. A comprehensive review was given of a dual magnetron sputtering technique to prodice low defect density a-Si, Ge:H. The controversy of the role of $\mathrm{F}$ in alloys continued to invoke lively discussions. Detailed information on photoconductivity and carrier lifetime of a-Si, $\mathrm{Ge}: \mathrm{H}$ alloys was presented along with the effect of varying deposition conditions. Also described were photo CVD deposited SiGe alloys which produced $5 \%$ cells and DC glow discharge techniques.

A comparison was made of a-Si:H and TFTs prepared in plasmas excited $13.56 \mathrm{MZ}$ and $60 \mathrm{~Hz}$. The properties of films produced by pyrolysis of disilane and photochemical vapor deposition were described.

The symposium was very well received and thus shall be an annual event. The next symposium will be held in conjunction with the 1986 MRS Spring Meeting in Palo Alto.

Symposium Support: Arco Solar, Inc., Energy Conversion Devices, Solar Energy Research Institute, Solarex, SPIRE Corporation, Standard Oil of Indiana (AMOCO), Standard Oil of Ohio, 3M Corporation.

Proceedings: Materials lssues in Applications of Amorphous Silicon Technology, edited by D. Adler, A. Madan, and M. J. Thompson. Prices until August 1 : MRS members-\$30, U.S! nonmembers- $\$ 36$, foreign nonmembers$\$ 42$. Prices after August 1 : MRS members $-\$ 35$, U.S. nonmembers $-\$ 42$, foreign nonmembers $-\$ 48$.

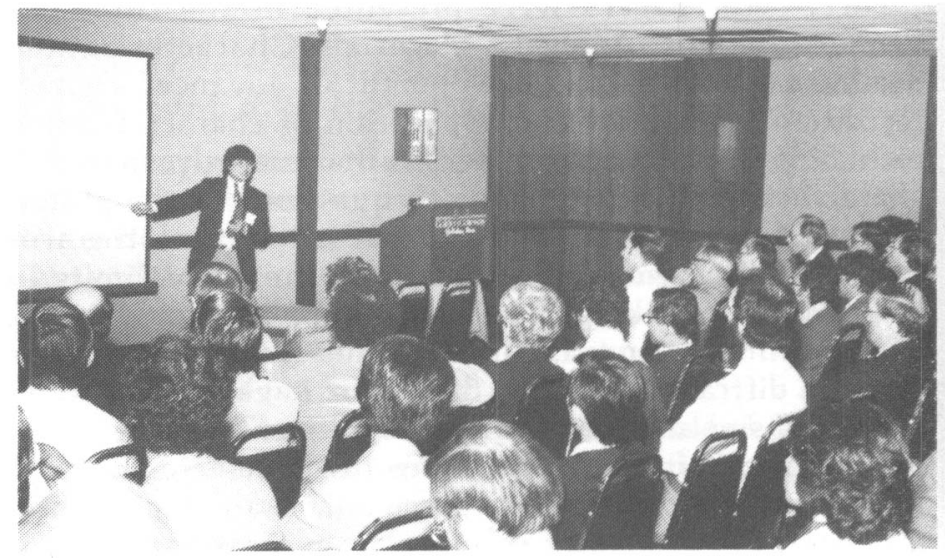


XUV and X-Ray Optics for Synchrotron Radiation (Symposium G)

Symposium Organizers: P. A. Pianetta, Stanford University; and J. Golovchenko, ATET Bell Laboratories.

The symposium on XUV and $x$-ray optics for synchrotron radiation was primarily concerned with reviewing the state of the art in optical systems and techniques which were being considered for use with synchrotron radiation. Toward this goal, a number of excellent talks were given for both near- and long-term applications.

The opening talks of the symposium covered the status of reflective optical systems. A variety of suggestions were made concerning novel optical systems which could be used with the new generation of high-power synchrotron sources, as well as on the importance of coherence on designs of advanced synchrotron radiation imaging systems. The subsequent talks were in the area of diffractive soft $x$-ray optics, in paticular, layered synthetic microstructures (LSMs) and transmission optics. It was generally agreed that the LSMs have reached a stage now where the surface finish of the substrate is the factor limiting performance, with the LSMs themselves reaching theoretical values. The session on transmission optics started with a discussion on the use of transmission gratings in spectroscopy. Then the topic shifted to zone plates and their use in $x$-ray microscopy, especially their use as lenses to focus soft $x-$ rays for a microprobe to study biological specimens.

The session on hard $x$-ray optics encompassed a variet $y$ of systems for monochromating $x$-rays on high-resolution

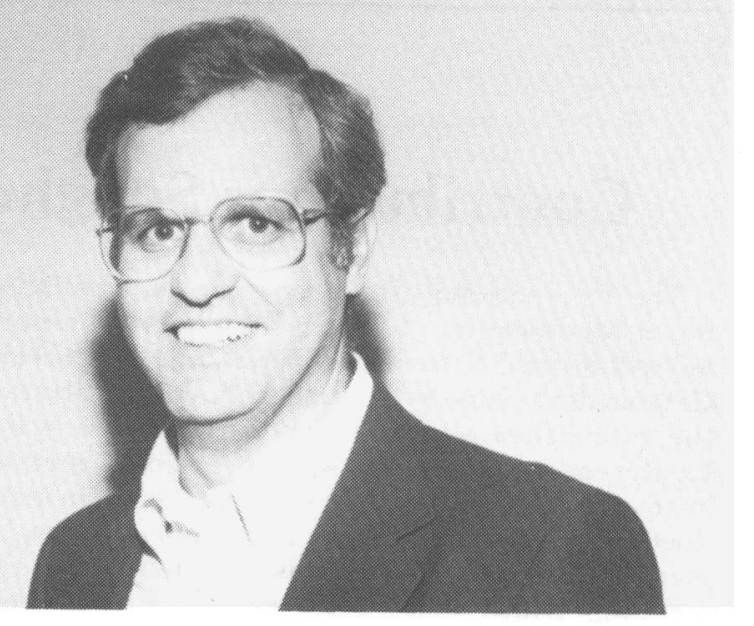

Symposium G Chairperson P. A. Pianetta.

or high-power beam lines. This included techniques for cooling crystals that were being placed in very intense wiggler beams. $X$-ray topography was also reviewed. The different techniques available with synchrotron radiation were discussed, and a number of examples of topographic studies were given. Finally, the area of $x$-ray detectors was covered. The detectors that were discussed were not originally designed for synchrotron radiation applications, but it was clear that applications would be found in the not-too-distant future once the detectors had been fully developed.

Symposium Support: Blake Industries and Microscience, Inc

MRS

\section{REGISTER EARLY}

\section{MRS Fall Meeting}

\author{
December 2-6, 1985 \\ Boston, Massachusetts
}

- 20 technical symposia

- Over 10 displays of analytical and processing equipment

Look for registration information in the mail.

\section{Washington Meeting Addresses Professional Society Meeting Restrictions}

Restrictions on the export of certain Materials Research Society was representechnical information which is in the public ted, at the request of MRS President domain within the United States may impact Kaufmann, by MRS member Robert Gotttechnical societies both directly and in- schall of the U.S. Department of Energy. directly-directly by the requirement that Gottschall indicated to the group that MRS technical sessions be closed to non-citizens is following this issue closely while having if they are to be run, and indirectly by had no specific experiences with it to date. inhibiting the planning of such information Further discussions in this area may exchanges and the submission of research follow from this meeting but no specific projects to such sessions. Such considera- statement of policy or call for action resulted tions were among the subjects discussed at from these particular discussions. President a meeting held at the National Academy of Kaufmann notes that "the MRS External Sciences in Washington, DC on April 5. Affairs Committee, chaired by $R$. L. The gathering was jointly sponsored by the Schwoebel, is keeping a close watch on the National Academy of Sciences, the National trends in this area as they relate to the Academy of Engineering, and the American activites of the Society."

Association for the Advancement of Science and was cochaired by their respective representatives, Frank Press (president of NAS), Robert White (president of NAE), and William Carey (executive officer of AAAS).

Twenty-three representatives of technical societies attended the meeting and took the opportunity to describe their organizations' experiences with restrictions on particular topics and their effect. The
When asked for MRS's reaction to the issues raised in these discussions, Kaufmann pointed out that "the Society has the dual obligation to act responsibly with regard to government regulations and national security and to promote the exchange of research information which is basic to scientific progress. Along with many other societies, MRS is hopeful of finding a productive way of fulfilling both." 